\title{
Are preventive measures adequate? An evaluation of the implementation of COVID-19 prevention and control measures in nursing homes in China
}

\section{Meihong Shi}

West China school of nursing Sichuan University/ West China Hospital,Sichuan Univeristy. Nursing Department, Southwest Medical University https://orcid.org/0000-0002-4349-7163

\section{Fengying Zhang}

West China of Nusing, Sichuan Univeristy/ West China Hospital

\section{Xinxin He}

Southwest Medical University

\section{Siyuan Huang}

Southwest Medical University

\section{MingFeng Zhang}

Southwest Medical University

Xiuying Hu ( $\nabla$ westchinahuxiuying@163.com )

https://orcid.org/0000-0003-1774-6370

\section{Research article}

Keywords: COVID-2019, Nursing homes, Prevention and control, Implementation, Evaluation

Posted Date: January 12th, 2021

DOl: https://doi.org/10.21203/rs.3.rs-46152/v2

License: (c) (i) This work is licensed under a Creative Commons Attribution 4.0 International License. Read Full License 


\section{Abstract}

Background: The novel coronavirus disease 2019 (COVID-19) pandemic has become a challenge for nursing homes in China. Nursing homes are particularly dangerous places regarding the spread of COVID19 given that they house vulnerable, high-risk populations. As such, several useful guidelines for coping with COVID-19 in nursing homes have been provided. However, the actual implementation rates of such guidelines are unknown. This study aims to document the adherence of nursing homes to the Ministry of Civil Affairs guidelines for COVID-19 prevention and control in nursing homes.

Methods: A cross-sectional study was conducted among 484 nursing homes in 136 cities of 28 provinces in China. A self-report questionnaire was created based on the Ministry of Civil Affairs guidelines for COVID-19 prevention and control in nursing homes (first edition). The questionnaire and the Transformational Leadership in the Public Sector Scale were sent to nursing home managers via the Wenjuanxing app online from February 7 to 29,2020 . A total of 461 responses were included in the analysis.

Results: The average overall implementation rate of COVID-19 prevention and control measures was $80.0 \%$ (143.97/180). The average implementation rates for hygienic behaviour management, access management were lower, with $75.3 \%$ and $78.7 \%$ respectively. The number of medical staff, established a quarantine unit (room), leadership's three dimensions included intellectual stimulation, individualized consideration, and idealized influence were found to affect the prevention and control implementation $(p<0.05)$. Nursing homes that did not have hospital-nursing home cooperation, did not have medical staff, and had not established a quarantine unit (room) had low implementation rates $(p<0.01)$. 69.8\% (332/461) of nursing home managers reported they had serious resource problems, inadequate of protective supplies (72.0\%) and staff shortage $(47.7 \%)$ were two primary problems.

Conclusion: Overall, the implementation of prevention and control measures by nursing homes are insufficient during the epidemic in China. Further education for staff, provide support to staff, supply adequate protective resources, and cooperation with hospitals are required to improve the implementation rate. It is urgent for nursing homes keep the safety of the residents and staff.

\section{Background}

The COVID-19 pandemic has affected the entire world [1], with more than 75.7million confirmed cases and 1.6 million casualties by December 22, 2020 (WHO). As the COVID-19 pandemic has continued, it has challenged the health system and impacted the lives of humans around the world. Given the absence of effective pharmaceutical interventions, non-pharmacological interventions (NPIs) are required to decrease disease transmission[2]. The adoption of non-pharmaceutical interventions such as mass confinement, social isolation, increased sanitation, and strict quarantine measures has proven to be beneficial in containing the virus [3]. 
Nursing homes are particularly dangerous places regarding the spread of COVID-19 given that they house vulnerable, high-risk populations. Older people are susceptible to novel coronavirus pneumonia $[4,5]$. Approximately $12.6 \%$ of the nearly 55 million adults aged 65 and over suffer from respiratory illness in the USA [6]. This high prevalence of respiratory illness among the elderly population explains why COVID19 is particularly lethal among this age group. Elderly residents of nursing homes are considered extremely vulnerable to COVID-19 exposure, infection, and disease consequences due to their high incidence of chronic disease and poor health in general. Furthermore, nursing homes provide an ideal environment for the spread of COVID-19 [7], as residents often live together in a crowded place, share sources of air and food, and share bedrooms and bathrooms. In the case of older vulnerable residents who usually require close care and therefore cannot completely adhere to social distancing guidelines both the residents and the workers around them are at high risk of becoming infected with COVID-19 [8]. There was an increasing number of reports referencing the spread of COVID-19 among nursing homes in Hungry [7] and in Canada [9]. COVID-19 has also been documented in most nursing homes throughout the United States [10, 11]. As of May 28, 2020, 7,500 American nursing homes reported 217,000 COVID-19 cases, and more than 44,000 coronavirus deaths had been reported in nursing and long-term care facilities, accounting for $50 \%$ of the country's deaths to date [12]. $24 \%$ of staff in nursing homes got infected [13]. In European countries, such as Italy [14], Spain [15], and England [16], 40\% 57\% of all COVID-19 deaths have occurred in nursing homes. Outbreaks in nursing homes can threaten the health care system[17], and the immediate implementation of prevention and control measures in nursing homes is needed. As such, several useful guidelines on coping with COIVD-19 in nursing homes have been provided [18-20].

Approximately 4 million people reside in 31,997 nursing homes in China. Nursing home administrators faced challenges related to the potential spread of COVID-19 infections in nursing homes in late 2019. At the beginning of the COVID-19 pandemic, from managers to the staff had no plan for the pandemic. There was no definite treatment for COVID-19, and prevention was considered the best possible defence at their disposal at that moment. Guidance for nursing homes did not become available until January 28 , 2020. The Ministry of Civil Affairs published the first edition of the guidelines for COVID-19 prevention and control in nursing homes, which provided prevention and control measured to address the urgent issue. In these guidelines, the minimum standards for nursing homes were published.

All of the nursing homes in China faced the threat of COVID-19 and implemented similar strategies following the guidance of the Ministry of Civil Affairs, but the extent of their preparedness, the swiftness with which the decisions were made and the scale of the measures varied. This paper focuses on adherence to guidelines for reducing virus transmission in nursing homes in China. We argue that there is an urgent need to evaluate the implementation rate of prevention and control measures in different nursing homes and analyse the factors related to their implementation.

\section{Methods}


This was a cross-sectional study conducted online. We searched for open-access information about nursing homes on the Civil Affairs websites of all provinces of China. We used a computerized random number generator to draw a sample of 480 nursing homes, which included approximately $1.5 \%$ of all nursing homes in China. Given the high decline rate in the online survey, we drew another sample of 480 nursing homes as reserve nursing homes in case institutions declined to participate. We called the nursing homes and described the goal of our survey and asked if they would be interested in participating in our survey. In the first phase, of the 480 invited nursing homes, 270 institutions declined to participate. In the second phase, of the remaining 480 nursing homes, 206 nursing homes declined. Finally, 484 nursing homes agreed to participate in our survey.

\section{Participants}

Eligible participants were the managers of the 484 nursing homes. We added the managers as friends on the WeChat app, which is a social connection application widely used in China, and sent them the questionnaire through the app. The inclusion criteria were as follows: managers who were in charge of nursing homes, elderly care settings, or long-term care facilities in China and who agreed to fill out the questionnaire online. The exclusion criteria were a lack of knowledge about the nursing home's actual situation and the completion of the questionnaire too quickly (in less than $120 \mathrm{~s}$ ).

\section{Basic information}

Basic information question included demographic characteristics of manager, nursing home characteristics, nursing home's problems and need during the pandemic. Basic information was identified as categorical factors.

\section{Questionnaire}

First Phase: Development of the Questionnaire Items

The questionnaire was titled "A survey of the implementation of the prevention and control of COVID-19 in nursing homes during the pandemic". Fifty-two items related to implementation of prevention and control measures were created based on the Ministry of Civil Affairs guidelines for COVID prevention and control in nursing homes (first edition) [18]. We invited ten managers of nursing homes to read the items to help us make the questionnaire clearer.

Second Phase: Content Validity and construct validity of the Questionnaire Items

We tested the questionnaire content validity with 14 experts (geriatric care specialists, psychologists, public health specialists, nursing management specialists). The experts were required to rate the relevance of each item on a 4-point Likert scale from 1 ("completely irrelevant") to 4 ("completely relevant"). The experts were asked to give the revising suggestions about the questionnaire. We revised those items with similar content or unclear expressions with the suggestions from experts. A cut-off of 
0.78 for I-CVI was used for item retention [21]. After removing 13 irrelevant items, the S-CVI of the questionnaire was calculated. The content validity of the entire questionnaire was 0.810 .

Exploratory factor analysis (EFA) was performed to estimate the construct validity. Total variance explained (\%) was $57.79 \%$ which satisfied the requirement of Kaiser-Mayer-Olkin values (0.834) and significant Bartlett's test of sphericity $(p<0.001)$, these coefficients all lie within the acceptable range [22]. At last, 36 items were divided into four aspects based on the factor analysis and professional judgment: basic management (7 items), access management (10 items), environmental disinfection management (7 items), and hygiene behaviour management (12 items).

\section{Third Phase: Testing of the Questionnaire}

The questionnaire was sent to the managers of nursing homes. Managers were required to complete the questionnaire based on the nursing home's actual situation. Managers were asked to indicate the frequency of the implementation of prevention and control measures in accordance with the recommendations of the Ministry of Civil Affairs in the nursing home they worked at during the last week on a 5 -point Likert scale ( $1=$ never, $2=$ rarely, $3=$ sometimes, $4=$ =most of time, $5=$ =always). The total implementation score was the sum of all the scores of 36 items. The higher the total implementation score was, the better the overall implementation of prevention and control in the nursing home was. Average implementation rate $=($ every item mean $\div$ every item maximum $) \times 100 \%$. The higher average implementation rate of the item was, the better prevention and control implementation for this item was.

\section{Scale}

We used the Scale "The Transformational Leadership in the Public Sector Scale" in this survey, which was developed by Chinese author Wang Junxia in 2018 [24]. The Scale was based on the theory of Bass and Avolio's transformational leadership. Considering nursing home's social and public characteristics, we used this Scale to explore the relationship between the transformational leadership of the manager and the prevention and control implementation rate. The Scale contained four dimensions: intellectual stimulation (4 items), inspirational motivation (2 items), individual care (3 items), and idealized influence (4 items). (Table 2) The Cronbach's alpha coefficient of the Scale was 0.927 reported by the author. The scale was scored using a 5 -point Likert scale $(1=$ Strongly disagree to $5=$ Strongly agree). Higher scores indicated higher levels of transformational leadership of nursing home manager.

\section{Data Collection}

The questionnaire and the Transformational Leadership in the Public Sector Scale were sent to the participants via the Wenjuanxing app, which is an e-questionnaire app. All questions in the questionnaire were required to be answered, and the questionnaire could not be submitted if it was not complete. The survey was conducted between February 7 and February 29, 2020, approximately two weeks after the beginning of the roll-out of the quarantine across China. Finally, we received 484 unique responses. After 
duplicates (from managers in the same nursing home or the same manager) and unqualified responses were removed, the final sample included 461 responses, with an analytic response rate of $48.0 \%$.

\section{Data analysis}

We used IBM SPSS Statistics (version 25.0, IBM Corporation) for data analysis. A descriptive analysis was performed by percentile. The count data were expressed as the constituent ratio. The Wilcoxon test, Kruskal-Wallis test, Spearman correlation, Multivariate linear regression analysis, and Binary logistic regression analysis were used for statistical analysis.

\section{Results}

\section{Characteristic of nursing home}

The sample was $43.0 \%$ women $(n=198)$, and the average age was 43.0 years $(S D=10.46$, range $=20-78$ years). Managers were from 461 nursing homes in 134 cities in 28 provinces, and the average tenure in the current nursing home was 6.6 years ( $S D=5.4$, range 1 to 30 years). A total of $4.3 \%$ of managers had a Master's degree or above, $33.0 \%$ of managers had a Bachelor's degree, $38.0 \%$ of managers had a technical college degree, $18.0 \%$ of managers had a high school diploma, and $6.7 \%$ had a junior high school diploma. There were 63188 older adults living in the 461 nursing homes, who were cared for by 16057 staff members (including managers, administrators, medical staff, nurse aides, and other staff members).

Table 1 showed the nursing home characteristics. Nursing homes that lacked medical support, such as those that did not have hospital-nursing home cooperation, did not have medical staff, and had not established a quarantine unit (room), had low prevention and control implementation rates $(p<0.01)$. Nursing homes that were government-owned, located in rural areas, were small ( $<100$ beds), and had a ratio of elderly residents to nurse aides above 15.00 also had low implementation scores $(p<0.05)$. (Table 1) 
Table 1 Characteristics of the nursing homes and prevention and control implementation scores

\begin{tabular}{|c|c|c|c|c|c|}
\hline \multirow[t]{2}{*}{ Characteristic } & \multicolumn{2}{|c|}{ Nursing homes } & \multirow{2}{*}{$\begin{array}{c}\text { Total implementation score } \\
\text { Median (P25, P75) }\end{array}$} & \multirow[t]{2}{*}{$\mathrm{H}$ or $\mathrm{Z}$ value } & \multirow[t]{2}{*}{ p-value } \\
\hline & $\mathbf{n}$ & $\%$ & & & \\
\hline \multicolumn{6}{|l|}{ Ownership } \\
\hline Government-owned & 93 & 20.2 & $145.0(117.5,157.5)$ & 8.984 & $0.011^{*}$ \\
\hline Private-owned & 287 & 62.3 & $151.0(133.0,162.0)$ & & \\
\hline Government-built, for-profit management & 81 & 17.5 & $149.0(136.5,162.5)$ & & \\
\hline \multicolumn{6}{|l|}{ Location } \\
\hline Rural & 75 & 16.3 & $145.0(113.0,159.0)$ & -2.349 & $0.019^{*}$ \\
\hline Urban & 386 & 83.7 & $150.0(113.0,161.0)$ & & \\
\hline \multicolumn{6}{|l|}{ Nursing home size (number of beds) } \\
\hline Small ( $<100$ beds) & 149 & 32.3 & $147.0(123.0,159.0)$ & 7.018 & $0.015^{*}$ \\
\hline Medium ( $100-200$ beds) & 160 & 34.7 & $148.5(132.0,160.0)$ & & \\
\hline Large (more than 200 beds) & 152 & 33.0 & $152.5(135.2,164.0)$ & & \\
\hline \multicolumn{6}{|l|}{ Ratio of elderly residents to nurse aides } \\
\hline$>15.00$ & 50 & 10.8 & $139.0(112.5,158.7)$ & 6.250 & $0.044^{*}$ \\
\hline $10.01 \sim 15.00$ & 34 & 7.4 & $148.5(125.5,159.0)$ & & \\
\hline$\leq 10.00$ & 377 & 81.8 & $151.0(133.0,161.0)$ & & \\
\hline \multicolumn{6}{|l|}{ Presence of hospital-nursing home cooperation } \\
\hline No & 353 & 76.6 & $147.0(128.5,160.0)$ & -2.62 & $0.009^{* \pm}$ \\
\hline Yes & 108 & 23.4 & $155.0(140.0,162.0)$ & & \\
\hline \multicolumn{6}{|l|}{ Number of medical staff } \\
\hline None & 91 & 19.7 & $137.0(112.0,158.0)$ & 26.755 & $0.000^{ \pm *}$ \\
\hline $1 \sim 5$ & 199 & 43.2 & $148.0(131.0,160.0)$ & & \\
\hline $6 \sim 10$ & 52 & 11.3 & $154.0(135.7,166.7)$ & & \\
\hline $11 \sim 20$ & 51 & 11.0 & $155.0(143.0,162.0)$ & & \\
\hline$>20$ & 68 & 14.8 & $155.0(143.0,164.7)$ & & \\
\hline \multicolumn{6}{|l|}{ Establishment of quarantine room/unit } \\
\hline None & 70 & 15.2 & $148.0(129.0,157.0)$ & 15.862 & $0.000^{ \pm *}$ \\
\hline Quarantine room & 256 & 55.5 & $147.0(107.0,160.0)$ & & \\
\hline Quarantine unit & 135 & 29.3 & $155.0(124.0,165.0)$ & & \\
\hline
\end{tabular}

Notes: ${ }^{* *} p<0.01, * p<0.05$

\section{Transformational leadership of nursing home's manager}

The average leadership score of the nursing home's manager was $56.03 \bigotimes T a b l e 2 \rrbracket .33 .8 \%$ of nursing home's managers got the transformational leadership score $50,20.2 \%$ of managers got the transformational leadership score between 50 to $60,46.0 \%$ of managers got the transformational leadership score above 60. 


\begin{tabular}{llll}
\hline Que & Items & Maximum & Mean \\
& & 20 & 16.78 \\
\hline Intellectual stimulation & 5 & 4.49 \\
Q1 & I will encourage staff to explore new and better way to do things & 5 & 4.11 \\
Q2 & I will empower employees to participate in important decisions & 5 & 4.44 \\
Q3 & I will revard creativity and innovation & 5 & 3.75 \\
Q4 & I encourage staff to look at things critically & 10 & 8.48 \\
Inspirational motivation & 5 & 4.14 \\
Q5 $\quad$ I will make the staff feel that they have been given the appropriate power & 5 & 4.34 \\
Q6 & I make the staff feel like they are family members of nursing homes & 15 & 12.89 \\
Individualized consideration & 5 & 4.24 \\
Q7 & I will let the staff to balance at family and at work & 5 & 4.38 \\
Q8 & I will give staff enough opportunity to use their talents & 5 & 4.28 \\
Q9 & I will give staff a chance to show their leadership & 5 & 17.88 \\
Idealized influence & 20 & 4.48 \\
Q10 & I have always maintained a high level of honesty and integrity & 5 & 4.41 \\
Q11 & I can fairly resolve grievances and disputes within the organization & 5.44 \\
Q12 & I have been courageous in the pursuit of truth & 5 & 4.44 \\
Q13 & I have always had a genuine desire to serve the people \\
Total score of transformational leadership & 5 & 4.55 \\
\hline
\end{tabular}

\section{Implementation score and average implementation rate}

The average implementation rate of COVID-19 prevention and control measures in nursing homes was $80.0 \%$. Managers reported a high average level of compliance with guidelines for the basic management of nursing homes, with an average implementation rate of up to $90.4 \%$, followed by the environmental disinfection management (79.0\%). The average implementation rates for access management and Hygiene behaviour management had the lowest rate, with 78.7 and $75.3 \%$ respectively. (Table 3 ). 


\begin{tabular}{|c|c|c|c|}
\hline Items & Maximum & Mean & $\begin{array}{l}\text { Average } \\
\text { implementation } \\
\text { rate (\%) }\end{array}$ \\
\hline 1 Basic management & 35 & 31.64 & 90.4 \\
\hline $\begin{array}{l}1.1 \text { Implement home quarantine or in-nursing home quarantine for elderly residents } \\
\text { who have left the nursing home }\end{array}$ & 5 & 4.70 & 94.0 \\
\hline 1.2 Monitor body temperature of residents and staff & 5 & 4.07 & 81.4 \\
\hline 1.3 Conduct bedroom patrol and daily active monitoring of symptoms. & 5 & 4.52 & 90.4 \\
\hline $\begin{array}{l}1.4 \text { Provide residents with emotional support and psychological counselling during } \\
\text { the pandemic }\end{array}$ & 5 & 4.07 & 81.4 \\
\hline $\begin{array}{l}1.5 \text { Train staff to address COVID-19 and provide guidance for employees regarding } \\
\text { the COVID-19 outbreak }\end{array}$ & 5 & 4.69 & 93.8 \\
\hline 1.6. Keep an eye on the epidemic & 5 & 4.80 & 96.0 \\
\hline 1.7 Report to the local public health authorities and follow the guidance & 5 & 4.81 & 96.2 \\
\hline 2 Access management & 50 & 39.35 & 78.7 \\
\hline $\begin{array}{l}2.1 \text { Notify elderly residents and family members of the suspension of all visitors to the } \\
\text { nursing home }\end{array}$ & 5 & 4.88 & 97.6 \\
\hline 2.2 Prohibit any visitors unless it is for "an end-of-life situation". Register the visitor & & & \\
\hline $\begin{array}{l}\text { and monitor the temperature of visitors, and require them to wear face masks and } \\
\text { disinfect their hands }\end{array}$ & 5 & 3.66 & 73.2 \\
\hline 2.3 Arrange special reception rooms in the nursing home. Permit visitors in the & & & \\
\hline $\begin{array}{l}\text { reception room only under special circumstances, prohibit them from entering the } \\
\text { living area }\end{array}$ & 5 & 2.94 & 58.8 \\
\hline 2.4 Offer staff accommodation in nursing homes & 5 & 3.94 & 78.8 \\
\hline 2.5 Perform centralized management of the accommodation site for staff & 5 & 2.33 & 46.6 \\
\hline $\begin{array}{l}2.6 \text { Require staff vho enter the nursing home to wear face masks and disinfect their } \\
\text { hands }\end{array}$ & 5 & 3.24 & 64.8 \\
\hline $\begin{array}{l}2.7 \text { Suspend all activities (consulting and reception services and unnecessary } \\
\text { volunteer activities and social practices) }\end{array}$ & 5 & 4.61 & 92.2 \\
\hline 2.8 Suspend the acceptance of new elderly residents & 5 & 4.66 & 93.2 \\
\hline 2.9 Do not permit the residents to go out & 5 & 4.75 & 95.0 \\
\hline 2.10 Arrange for one staff member to receive daily necessities, ordered materials and & & & \\
\hline $\begin{array}{l}\text { other packages from family members and disinfect them with } 75 \% \text { alcohol or chlorine } \\
\text { disinfectant before giving them to the elderly residents }\end{array}$ & 5 & 4.32 & 86.4 \\
\hline 3 Environmental disinfection management & 35 & 27.65 & 79.0 \\
\hline 3.1 Open windows for ventilation and improve air flow at least twice per day & 5 & 4.35 & 87.0 \\
\hline 3.2 Wipe the residents' bedrooms with clean water at least twice per week & 5 & 3.63 & 72.6 \\
\hline $\begin{array}{l}\text { 3.3 Disinfect the residents' bedrooms with chlorine disinfectant at least twice per } \\
\text { week }\end{array}$ & 5 & 3.84 & 76.8 \\
\hline $\begin{array}{l}3.4 \text { Wipe offices and service areas, including switches, elevator buttons, doorknobs, } \\
\text { handrails, faucets, tables, and chairs, with clean water at least twice per week }\end{array}$ & 5 & 3.52 & 70.4 \\
\hline $\begin{array}{l}3.5 \text { Disinfect offices and sevice areas, including switches, elevator buttons, } \\
\text { dnnrknnhs hancrails faureats tables and chairs with chlorine disinffertant at least } \\
\text { twice per week }\end{array}$ & 5 & 3.77 & 75.4 \\
\hline $\begin{array}{l}3.6 \text { Disinfect the kitchen, toilet, laundry, and garbage disposal areas vith chlorine } \\
\text { disinfectant at least once per day }\end{array}$ & 5 & 3.94 & 78.8 \\
\hline 3.7 Disinfect dining and drinking utensils at least three times per day & 5 & 4.58 & 91.6 \\
\hline 4 Hygiene behaviour management & 60 & 45.22 & 75.3 \\
\hline $\begin{array}{l}\text { 4.1 Ask the residents to wash and disinfect their hands and maintain personal } \\
\text { hygiene and help them do so }\end{array}$ & 5 & 4.03 & 80.6 \\
\hline 4.2 Ask elderly residents to close the toilet lid before flushing & 5 & 3.40 & 68.0 \\
\hline $\begin{array}{l}\text { 4.3 Avoid eating together or communal meals, maintain physical distance, and } \\
\text { suspend group activities }\end{array}$ & 5 & 3.85 & 77.0 \\
\hline $\begin{array}{l}\text { 4.4 Provide knowledge education to the residents about COVID-19 prevention and } \\
\text { control }\end{array}$ & 5 & 3.11 & 62.2 \\
\hline 4.5 Have staff wear face masks during vorking time & 5 & 4.50 & 90.0 \\
\hline 4.6 Have residents wear face masks in public areas of the nursing home & 5 & 3.02 & 60.4 \\
\hline $\begin{array}{l}4.7 \text { Have staff and residents wear face masks as appropriate and change into new } \\
\text { face masks }\end{array}$ & 5 & 2.96 & 59.2 \\
\hline $\begin{array}{l}\text { 4.8 Have staff wash their hands with soap and water or disinfect their hands using } \\
\text { alcohol-based hand sanitizers before touching the residents }\end{array}$ & 5 & 3.70 & 74.0 \\
\hline $\begin{array}{l}4.9 \text { Have staff wash their hands vith soap and water or disinfect their hands using } \\
\text { alcohol-based hand sanitizers after touching the residents }\end{array}$ & 5 & 3.78 & 75.6 \\
\hline 4.10 Ensure that staff appropriately dispose of garbage, sewage and fitth & 5 & 4.13 & 82.6 \\
\hline $\begin{array}{l}\text { 4.11 Ensure that staff dispose or disinfect them face masks safely, without causing } \\
\text { contamination. }\end{array}$ & 5 & 4.13 & 82.6 \\
\hline 4.12 Have staff implement administrative provisions related to food safety & 5 & 4.52 & 90.4 \\
\hline Total Implementation Score & 180 & 143.97 & 80.0 \\
\hline
\end{tabular}

A high proportion of nursing homes unable to adhere to the guideline strictly in some important items (Fig. 1). For example, Item 2.3 and Item2.5 were related to staff access management, Item2.2 and Item 2.6 were related to visitor policy. Item 4.6,4.7,4.8 were related to measures of wearing face masks, Item 4.4 was related to knowledge education to residents. 
Multivariate linear regression analysis was used to analyse the factors which were closely related (Table 4). The factors included number of medical staff, establishment of a quarantine room/unit, intellectual stimulation, individualized consideration, and idealized influence, which were eventually proved to affect the prevention and control implementation scores $(p<0.05) . R^{2}=0.231$, adjusted $R^{2}=0.223, F=27.353$, $p<0.001$.

Table 4 Multivariate linear regression analysis of prevention and control implementation scores

\begin{tabular}{llllll}
\hline Variables & B & S.E. & Beta & t & p-value \\
\hline constant & 60.898 & 8.113 & & 7.506 & 0.000 \\
Number of medical staff & 2.875 & 0.740 & 0.167 & 3.887 & 0.000 \\
Establishment of a quarantine room/unit & 3.195 & 1.494 & 0.092 & 2.138 & 0.033 \\
Intellectual stimulation & 0.999 & 0.495 & 0.123 & 2.017 & 0.044 \\
Individualized consideration & 1.942 & 0.795 & 0.168 & 2.444 & 0.015 \\
Idealized influence & 1.672 & 0.651 & 0.162 & 2.567 & 0.011 \\
\hline
\end{tabular}

\section{Resource problem of the nursing homes}

We investigated the resource problems of nursing homes during the pandemic. The results showed that the primary need was protective supplies. $72.0 \%$ of the nursing homes reported a lack of protective supplies. The second problem of the nursing homes was staff shortages, account $47.7 \%$ (Fig. 2).

$69.8 \%$ (332/461) of nursing home managers reported they had serious resource problems, $30.2 \%$ $(139 / 461)$ of nursing home managers reported they had not been involved in serious resource problems. We used binary logistic regression analysis to find the factors related to the nursing home with serious resource problems (Table 5). The result showed nursing home located in urban (OR=0.315, 95\% Cl: $0.127 \sim 0.779$ ), nursing home size is large (more than 200 beds) ( $\mathrm{OR}=0.232,95 \% \mathrm{Cl}: 0.129 \sim 0.419$ ), have hospital-nursing home cooperation and manager's transformational leadership score $>60$ (OR=0.577, 95\%Cl: $0.343 \sim 0.970$ ) were protective factors. Nursing homes with these factors had a lower risk of involving in serious problems. 
Table 5 Binary logistic regression analysis of factors related to the nursing home with serious resource problems

\begin{tabular}{|c|c|c|c|c|}
\hline \multirow[b]{2}{*}{ Variables } & \multicolumn{2}{|c|}{ Nursing home } & \multirow[b]{2}{*}{ OR $(95 \% \mathrm{Cl})$} & \multirow[b]{2}{*}{ p-value } \\
\hline & $\begin{array}{l}\text { without serious } \\
\text { resource } \\
\text { problems } \\
(\mathrm{n}, \%)\end{array}$ & $\begin{array}{l}\text { with serious } \\
\text { resource } \\
\text { problems } \\
(\mathrm{n}, \%)\end{array}$ & & \\
\hline \multicolumn{5}{|l|}{ Location } \\
\hline Rural & $6(4.3)$ & $69(21.4)$ & 1.000 & \\
\hline Urban & $133(95.7)$ & $253(78.6)$ & $0.315(0.127 \sim 0.779)$ & 0.012 \\
\hline \multicolumn{5}{|l|}{ Nursing home size } \\
\hline Small ( $<100$ beds) & $21(15.1)$ & $128(39.8)$ & 1.000 & \\
\hline Medium (100-200 beds) & $39(28.1)$ & $121(37.6)$ & $0.656(0.356 \sim 1.209)$ & 0.174 \\
\hline Large (more than 200 beds) & $79(56.8)$ & $73(22.6)$ & $0.232(0.129 \sim 0.419)$ & 0.000 \\
\hline \multicolumn{5}{|c|}{ Presence of hospital-nursing home cooperation } \\
\hline No & $80(57.6)$ & $273(84.8)$ & 1.000 & \\
\hline Yes & $59(42.4)$ & $49(15.2)$ & $0.344(0.212 \sim 0.559)$ & 0.000 \\
\hline \multicolumn{5}{|c|}{ Transformational leadership score } \\
\hline$<50$ & $34(24.5)$ & $122(37.9)$ & 1.000 & \\
\hline $50 \sim 60$ & $30(21.5)$ & $63(19.5)$ & $0.721(0.383 \sim 1.357)$ & 0.311 \\
\hline$>60$ & $75(54.0)$ & $137(42.5)$ & $0.577(0.343 \sim 0.970)$ & 0.038 \\
\hline
\end{tabular}

\section{Discussion}

\section{Medical support is a key point in helping nursing homes face the threat of COVID-19}

The COVID-19 outbreak spread rapidly across the world. Nursing homes are high-risk settings and face unprecedented challenges. Various preventive measures were implemented in nursing homes in China, including lockdowns, the restriction of visitors, the prohibition of the entry of the people from Wuhan City, 14-day isolation for returning staff and residents, and symptom monitoring for all of the staff and residents. Despite these strict measures, COVID-19 still found its way into 3 nursing homes in Wuhan Province in China that were included in this survey. We must be aware of the many problems and weaknesses in the management of nursing homes. In this study, the average overall implementation rates of COVID-19 prevention and control measures was $80.0 \%$ (143.97/180), which was at the medium level. The staff and residents in nursing homes generally lacked awareness, knowledge, and basic skills for preventing the spread of infectious disease, which made the guidelines insufficient. The study shows that nursing homes that lack medical support had low implementation rates. In particular, the number of medical staff and the establishment of a quarantine room/unit were two critical factors that affected the implementation score. $(p<0.05)$. The finding indicates that medical staff in nursing homes are poised to play a pivotal role in improving the implementation of COVID-19 prevention and control measures. They could provide services to residents directly, be responsible for operating the quarantine room/unit, and provide training to other staff. However, not all nursing homes had doctors and nurses on their staff. The 
USA's research also showed similar result that the nursing home with health care worker represents a lower mortality rate compared with facilities without health care worker [25]. In our survey, there were no medical staff (doctors, nurses, or pharmacists) in $19.7 \%$ of the nursing homes, as nursing homes tend to strive to create a family environment rather than a medical environment [26]. This scenario leads to preventive measures that cannot be closely followed. Studies in Singapore [27] and Spain [15] suggest that public healthcare workers should be sent into nursing homes to help improve preparedness for and the prevention and control of COVID-19. A study in Canada also reported the experience of the emergency response of an acute-care hospital to a nursing home [28]. Such hospital-nursing home partnerships are a new form of cooperation that has arisen during the COVID-19 pandemic.

\section{A shortage of nurse aides in nursing homes was a significant problem}

Nursing homes often face nurse aide shortages, which have been exacerbated by the current pandemic situation. Nurse aides have to work long shifts, perform high-intensity labour and complete a large amount of extra work during the pandemic because the nursing homes are experiencing high levels of absenteeism. The pandemic coincided with the Spring Festival. Some nurse aids who went home to reunite with their families were unable to return. Nurse aide shortages not only directly affect the achievement and maintenance of care quality in nursing homes but also indirectly affect the implementation of COVID-19 prevention and control measures [10]. Most of the implementation measures were implemented by the nurse aides. However, nearly half $(47.7 \%)$ of the nursing homes reported staff shortages. Even before the pandemic, it was difficult to recruit qualified nurse aides in China. Nurse aides are often described as special groups with low social status, lower education level, insufficient training, and poor wages. Other countries face the same problem $[27,29,30]$. Policies should be designed to ensure that nursing homes are adequately staffed and that infection control protocols are implemented with high quality [17]. Common strategies include having nurse aides live in nursing home, extend their hours, asking nurse aides to sacrifice their rest time and encouraging the staff other than nurse aides to temporarily fill the nurse aide role. However, the execution of these strategies was difficult. It required a high level of leadership of the nursing home's manager. In our study, the three dimensions of transformational leadership, included intellectual stimulation, individualized consideration, and idealized influence, affecting the prevention and control implementation. The transformational leadership of the nursing home's manager was different from other types of leadership. It built the relationship between managers and staff based on loyalty, trust and respect [31]. Idealized influence played an important role. Manager elevated the moral level of staff with personal integrity [32]. It encouraged them to consciously prolong the work hours, increase workload, and implement prevention and control measures for making up for the shortage of staff.

\section{Little preparation for the pandemic}

COVID-19 has exposed long-standing problems in nursing homes. Given the shockingly high rates of infections and deaths in nursing homes, it is crucial for nursing homes to prepare. However, little planning for infectious disease pandemics has been undertaken in nursing homes. There was no absolute 
requirement for such planning in the previous policy. Furthermore, in terms of the management system, there is a lack of emergency response plans, emergency leadership committees and emergency supply reserve mechanisms in nursing homes. This is similar to the situation in other countries, such as Ireland [33] and the USA [17], where there is little preparation for pandemics in nursing homes. Even more troubling is that most nursing homes lack the essential materials to protect their residents and staff. In our survey, $69.8 \%$ (332/461) of nursing home managers reported they had serious resource problems, $72.0 \%$ of nursing homes reported their primary problem was inadequate protective supplies. They could not obtain access to the necessary supplies for prevention at the beginning of the pandemic. The shortage of protective supplies is still a problem in many countries [34]. 70\% of American nursing homes were unable to provide sufficient supplies for their staff [10]. In this light, nursing homes should reserve protective material for emergency use, intensify their efforts to acquire protective supplies during epidemics, improve access to essential resources, and develop optimal distribution strategies for when supplies are insufficient. During the pandemic period, there may be considerable pressure on nursing homes to maintain operation; $43.8 \%$ of the nursing homes reported having difficulties operating, and $25.6 \%$ of nursing homes reported an inadequate supply of daily necessities in this study. Given the similar lack of preparation and reserves in the nursing home sector during many other natural disasters [33], the COVID-19 pandemic raises questions regarding whether nursing home managers have learned from this experience. We found nursing homes those located in urban, had more than 200 beds, had hospital-nursing home cooperation, and higher transformational leadership of managers had a lower risk of involving serious resource problems. It indicates that the better the nursing home's comprehensive conditions, the stronger their ability to resist the risk of resource problem caused by the COVID-19 epidemic. A similar result from nursing homes in the USA showed that the nursing homes with higher quality ratings could control the spread of COVID-19 and decrease the death rate [35]. Because both the human resources and material resources of the high-quality nursing homes were relatively sufficient [36]. Nursing homes of China had to prepare enough human resources and material resources, making emergency response plans to avoid future crises.

\section{Access management should be strengthened}

COVID-19 is an ongoing pandemic that is challenging nursing homes due to its high infectivity. It is forcing the implementation of drastic measures in nursing homes [37]. Nursing homes have adopted strict access and visitation restrictions according to the provided guidelines [38]. Overall, the rate of adherence to the guidelines for access management among nursing homes in this study was $78.7 \%$. However, it is uncertain whether the level of adherence can be maintained throughout the pandemic period. Staff are most likely to cause imported transmission [39]. Staff movements between their homes and nursing home facilities could transmit the disease. A survey of Chinese nurse aides showed that $81 \%$ of nurse aides from a rural area with low educational level and low adaption of other work. $92 \%$ of nurse aides were inter-city migrants, and $62 \%$ of nurse aides were inter-provincial migrants. Unlike in other countries, Chinese nursed aides always worked for only one facility and did not have a second job. So $85 \%$ of nursing homes accommodated nurse aides [40]. However, in our survey, only $78.8 \%$ of nursing homes can provide staff accommodations in nursing homes. Therefore, $21.2 \%$ of nursing home staff 
have to go home. To decrease the risk of the spread of COVID-19, one infection control measure is to house the staff in the nursing homes, which might mitigate the risk associated with staff moving between their homes and the facilities during the pandemic. If there is no living space in the nursing home, the staff should be centrally managed in an accommodation site without having contact with others. The staff responsible for purchasing should not contact staff who provide services to the residents. Access management is the key form of management; if not strictly implemented, nursing homes will be placed at great risk.

During the COVID-19 epidemic, most nursing homes in China have been completely closed and had little contact with the external environment, with nobody entering and nobody exiting. In the early stage of the epidemic, nursing homes prohibited any visitors unless it is for "an end-of-life situation." Item 2.2 and Item 2.3 showed the strict visit policy. However, the average implementation rate of Item 2.2 and Item 2.3 were not high, with $73.2 \%$ and $58.8 \%$, respectively.

Lockdown and isolation are appropriate policies to limit the spread of COVID-19, but these measures impact people's mental health [3]. Some residents and staff often feel lonely, anxious and depressed, and they struggle with the absence of relatives. In our study, 38.0\% of elderly residents and staff needed psychological intervention during the lockdown period. It was unclear how long isolation will last by the time we finished our survey, but the situations may worsen as enforced isolation continues. Strictly lockdown policy made the family members and other volunteers' support care impossible, further exposing the vulnerabilities associated with staff shortage [10]. Manager's leadership might play an irreplaceable role in maintaining the stability of the nursing homes. Transformational leaders changed their staff and encouraged them to consider organizational goals over personal interests [41]. It made staff regard fighting the COVID-19 as a battle, making them view staying in the nursing home as heroic behaviour to guard the safety of nursing home.

\section{Problems with environmental disinfection management}

Environmental cleaning and disinfection are important precautionary measures to prevent indirect COVID19 infections. Kampf et al [42] reported that coronaviruses can live on surfaces for up to 9 days. Adopting environmental cleaning and disinfection measures has proven to be beneficial in containing the virus [43]. Therefore, the regular cleaning and disinfection of surfaces and objects are essential to control spread. However, the implementation rate of environmental disinfection management was only $79.0 \%$ in this study. The frequency of the cleaning and disinfection of residents' bedrooms and office areas and service places was insufficient (Item 3.2 to 3.5). Although most of the nursing homes had established infection disease prevention and control standards, the staff were insufficiently trained in infectious disease prevention and control skills. The local CDC should be responsible for providing training to the staff in nursing homes regarding disinfection knowledge, including information about what kinds of disinfectants are effective and how to disinfection can be performed effectively [44]. Sanitation and environmental disinfection should be carried out scientifically based on the recommended procedures 
[45]. Enhanced environmental cleaning and disinfection in nursing homes is important; it should be not a temporary task but should be routine work.

\section{Risk in Hygienic Behaviour Management}

Hygienic behaviour management is central to the transmission of COVID-19, and changing behaviour is crucial to prevent transmission. In our survey, the average implementation rate of hygienic behaviour management was only $75.3 \%$, which was the lowest rate among the four aspects of the implementation of COVID-19 prevention and control measures, indicating that hygienic behaviour management is the weakest point in nursing homes. In addition, the implementation rates of measures involving residents, such as having them wear face masks, providing them with education and maintaining physical distance, were extremely low, which may be related to the cognitive decline of some residents. Aktinson et al[46] reported that the size of respiratory droplets from humans typically range from 0.5 to $12 \mu \mathrm{m}$ and that droplets sized $<0.5 \mu \mathrm{m}$ can remain airborne for significant periods of time. Van Doremalen et al [47] found that COVID-19 remains stable in airborne aerosols for at least 3 hours and can persist on inanimate surfaces for 48 to 72 hours. Based on the above, personal protection in the form of improved hygiene behaviour [44], such as the appropriate utilization of face masks in public areas, may mitigate future COVID-19 transmission in nursing homes. Among the many considerations, forty-two percent of the elderly have dementia or cognitive decline in nursing homes [48], making the enforcement of mitigation strategies such as face mask wearing a major challenge [12]. Therefore, items related to wearing face masks as appropriate (Item4.6 to 4.8) showed lower average implementation rates. It has been a controversial issue whether residents must wear masks in nursing homes that are already completely closed. Given that elderly residents often have respiratory diseases [6], wearing face masks will affect their respiratory function, which can lead to decreased compliance.

Effective risk communication and knowledge education in the early stage of the COVID-19 outbreak is critical for promoting behavioural compliance. These strategies have proven to be useful for the general public [3] but have not been effectively adopted in nursing homes. The implementation rate for the item "Provide knowledge education to the residents about COVID-19 prevention and control" (Item 4.4) was also very low (64.0\%). For example, understanding why face masks should be used, why visitors are not coming to see them, and why they should keep distance from others is difficult for residents with dementia. It is also a major challenge for staff to provide education to these residents. The recommendation to "maintain physical distance" (Item 4.3) was also difficult for most elderly and staff. The implementation rate for this measure was $77.0 \%$. In China, residents who live in nursing homes have chronic underlying medical disorders; they usually have considerable personal care needs, including bathing, dressing, and toileting, which make maintaining physical distancing nearly impossible. Considering the characteristics of the residents, there are few strategies that can be used to improve the hygiene behaviour of residents. The best strategy is to prevent COVID-19 from invading nursing homes.

\section{Conclusion}


The COVID-19 pandemic is perhaps one of the greatest health threats the world has faced in this century, and it requires not only a cohesive effort but also enormous discipline to follow the guidelines. The current implementation of prevention and control measures is insufficient, and further improvement is required. We argue that effective interventions are urgently needed to increase the implementation rate of access management, environmental disinfection management, and hygienic behaviour management. Shortages in medical staff and nurse aides, a lack of preventive supplies, and little preparation for pandemics are common obstacles encountered by nursing homes. Currently, prevention and control work still being undertaken in all nursing homes to ensure a high level of preparedness to combat COVID-19 in China. Local officials must inspect nursing homes and provide help; they must ensure that nursing homes are adequately staffed, that the residents' needs are being met and that infection control procedures are being followed.

\section{Study considerations}

There were some limitations to this study. The survey was conducted online; although we used the random sampling method, more than half of the contacted nursing homes refused to participate in the survey. The results may have been affected by selection bias because of the high decline rate. Because of the limitation of resources, we couldn't investigate enough nursing homes. The nursing homes number was 461 , which less than the ideal sample size requirement of 490 . These results offer valuable insight into the nursing homes' adherence to the guidelines. The implementation of prevention and control measures in nursing homes was evaluated from managers' perspectives; therefore, caution should be exercised in generalizing these findings. Despite these limitations, to the best of our knowledge, this is the first study to evaluate the implementation of prevention and control measures in nursing homes during the early phase of the COVID-19 outbreak in China.

\section{Abbreviations}

COVID-19 - "coronavirus disease 2019". According to the World Health Organization, severe acute respiratory syndrome coronavirus 2 (SARS-CoV-2) is the official name of the virus that causes coronavirus disease 2019 (COVID-19).

CDC - Center for Disease Control and Prevention

PPE - personal protective equipment

\section{Declarations}

\section{Ethical approval and consent to participate}

Ethical approval for this study was obtained from the Institutional Review Board of the West China School of Medicine, Sichuan University (Approval number 2020-1270). All participants gave verbal 
informed consent.

\section{Consent for publication}

Not applicable

\section{Availability of data and material}

Questionnaire of implementation of the prevention and control of COVID-19 in nursing homes during the pandemic is provided as additional files.

\section{Competing interests}

The author(s) declare no potential conflicts of interest with respect to the research, authorship, and/or publication of this article.

\section{Funding}

This study was supported by the National Natural Science Foundation of China (Grant No. 71871147) and Luzhou Municipal People's Government-Southwest Medical University Science and Technology Strategic Cooperation Project. (Grant No. 2019LZXNYDR09).

\section{Authors' Contributions}

$\mathrm{SM}, \mathrm{ZF}$ and $\mathrm{HX}$ designed the study, and designed the questionnaire.SM, HX, HS, and ZM collected the data. SM analysed the data. SM, ZM and ZF interpreted the data. SM wrote the first draft of the manuscript. ZF and HX revised the manuscript for important intellectual content. All authors contributed to the final manuscript.

\section{Acknowledgements}

We thank all 461 nursing homes and their managers for participating in this study. We would like to thank the Association for the Aged of all provinces that provided help in obtaining access to the nursing homes. We would also like to thank Mr. Su Youcheng, Mr. Huang Zaijun, Mr. Shi Yongjin and Mr. Liu Wei for helping with data collection. We also thank Liu Li and Li Ailing for revising the manuscript.

\section{Author details}

${ }^{1}$ West China School of Nursing, Sichuan University/ Innovation Centre of Nursing Research, West China Hospital, Sichuan University, No. 37 Guo Xue Street, 610041, Chengdu, Sichuan Province, China. ${ }^{2}$ Nursing department of Southwest Medical University, No. 1 Xianglin Rode, Longmatan District, 646000, Luzhou, Sichuan, China.

\section{References}


1. Wu JT, Leung K, Leung GM: Nowcasting and forecasting the potential domestic and international spread of the 2019-nCoV outbreak originating in Wuhan, China: a modelling study. Lancet 2020, 395(10225):689-697.

2. Cowling BJ, Ali ST, Ng TWY, Tsang TK, Li JCM, Fong MW, Liao QY, Kwan MYW, Lee SL, Chiu SS et al: Impact assessment of non-pharmaceutical interventions against coronavirus disease 2019 and influenza in Hong Kong: an observational study. Lancet Public Health 2020, 5(5):E279-E288.

3. Lippi G, Henry BM, Bovo C, Sanchis-Gomar F: Health risks and potential remedies during prolonged lockdowns for coronavirus disease 2019 (COVID-19). Diagnosis 2020, 7(2):85-90.

4. Chen N, Zhou M, Dong X, Qu J, Gong F, Han Y, Qiu Y, Wang J, Liu Y, Wei Y et al: Epidemiological and clinical characteristics of 99 cases of 2019 novel coronavirus pneumonia in Wuhan, China: a descriptive study. Lancet (London, England) 2020, 395(10223):507-513.

5. Huang C, Wang Y, Li X, Ren L, Zhao J, Hu Y, Zhang L, Fan G, Xu J, Gu X et al: Clinical features of patients infected with 2019 novel coronavirus in Wuhan, China. Lancet (London, England) 2020, 395(10223):497-506.

6. Cohen MA, Tavares J: Who are the Most At-Risk Older Adults in the COVID-19 Era? It's Not Just Those in Nursing Homes. Journal of aging \& social policy 2020, 32(4):380-386.

7. Kemenesi G, Kornya L, Toth GE, Kurucz K, Zeghbib S, Somogyi BA, Zoldi V, Urban P, Herczeg R, Jakab F: Nursing homes and the elderly regarding the COVID-19 pandemic: situation report from Hungary. Geroscience 2020, 42(4):1093-1099.

8. Lynn J: Playing the Cards We are Dealt: Covid-19 and Nursing Homes. Journal of the American Geriatrics Society 2020, 68(8):1629-1630.

9. Béland D, Marier P: COVID-19 and Long-Term Care Policy for Older People in Canada. J Aging Soc Policy 2020, 32(4-5):358-364.

10. McGilton KS, Escrig-Pinol A, Gordon A, Chu CH, Zúñiga F, Sanchez MG, Boscart V, Meyer J, Corazzini $\mathrm{KN}$, Jacinto AF et al: Uncovering the Devaluation of Nursing Home Staff During COVID-19: Are We Fuelling the Next Health Care Crisis? J Am Med Dir Assoc 2020, 21(7):962-965.

11. Abrams HR, Loomer L, Gandhi A, Grabowski DC: Characteristics of U.S. Nursing Homes with COVID19 Cases. Journal of the American Geriatrics Society 2020, 68(8):1653-1656.

12. Abbasi J: "Abandoned" Nursing Homes Continue to Face Critical Supply and Staff Shortages as COVID-19 Toll Has Mounted. Jama 2020, 324(2):123-125.

13. Sacco G, Foucault G, Briere O, Annweiler C: COVID-19 in seniors: Findings and lessons from mass screening in a nursing home. Maturitas 2020, 141:46-52.

14. Trabucchi M, De Leo D: Nursing homes or besieged castles: COVID-19 in northern Italy. Lancet Psychiatry 2020, 7(5):387-388.

15. Rada AG: Covid-19: the precarious position of Spain's nursing homes. Bmj-British Medical Journal 2020, 369:m1586. 
16. Graham NJ, C; Downes, R; Sharp, DJ: SARS-CoV-2 infection, clinical features and outcome of COVID19 in United Kingdom nursing homes. $J$ Infect 2020, 6(03):20-29.

17. Gardner W, States D, Bagley N: The Coronavirus and the Risks to the Elderly in Long-Term Care. Journal of Aging \& Social Policy 2020, 32(4):310-315.

18. Guidelines for COVID prevention and control of nursing homes (First edition) [http://www.gov.cn/xinwen/2020-01/28/content_5472755.htm]

19. Amer Geriatrics S: American Geriatrics Society Policy Brief: COVID-19 and Nursing Homes. Journal of the American Geriatrics Society 2020, 68(5):908-911.

20. Arango VM: Confinement/Isolation: From the Preventive Language of COVID-19 to the Pragmatics of the War in Colombia. Geopoliticas-Revista De Estudios Sobre Espacio Y Poder 2020, 11:285-291.

21. Polit $D F$, Beek $C T$, Owen SV: Is the CVI an acceptable indicator of content validity? Appraisal and recommendations. \#N/A 2007, 30(4):459-467.

22. Tabachnick BGF, L.S: Using Multivariate Statistics. New York, NY, USA: Allyn and Bacon; 2007.

23. De Maria M, Ferro F, Ausili D, Alvaro R, De Marinis MG, Di Mauro S, Matarese M, Vellone E: Development and Psychometric Testing of the Self-Care in COVID-19 (SCOVID) Scale, an Instrument for Measuring Self-Care in the COVID-19 Pandemic. Int J Env Res Public Health 2020, 17(21):7834.

24. Wang J: Measurement and Empirical Study of Transformational Leadership in China Public Sectors. Journal of Beijing University of Aeronautics and Astronautics (Social Sciences Edition) 2018, 31(01):45-49+83.

25. Dean A, Venkataramani A, Kimmel S: Mortality Rates From COVID-19 Are Lower In Unionized Nursing Homes. Health Aff 2020, 39(11):1993-2001.

26. Aiello AE, Malinis M, Knapp JK, Mody L: The influence of knowledge, perceptions, and beliefs, on hand hygiene practices in nursing homes. Am J Infect Control 2009, 37(2):164-167.

27. Tan LF, Seetharaman SK: COVID-19 Outbreak in Nursing Homes in Singapore. Journal of microbiology, immunology, and infection = Wei mian yu gan ran za zhi 2020.

28. Stall NM, Farquharson C, Fan-Lun C, Wiesenfeld L, Loftus CA, Kain D, Johnstone J, McCreight L, Goldman RD, Mahtani R: A Hospital Partnership with a Nursing Home Experiencing a COVID-19 Outbreak: Description of a Multiphase Emergency Response in Toronto, Canada. Journal of the American Geriatrics Society 2020, 68(7):1376-1381.

29. Spetz J SR, Chapman S, Bryant N.: Home and community-based work-force for patients with serious illness requires support to meet growing needs. Health Aff 2019, 38(6):902-909.

30. Statistics BoL: Occupational Outlook Handbook, Nursing Assistants and Orderlies. In. Edited by Washington D. Bureau of Labor Statistics; 2020.

31. Afsar B, Umrani WA: Does thriving and trust in the leader explain the link between transformational leadership and innovative work behaviour? A cross-sectional survey. Journal of Research in Nursing 2020, 25(1):37-51. 
32. Lan Y, Chen Z: Transformational Leadership, Career Adaptability, and Work Behaviors: The Moderating Role of Task Variety. Front Psychol 2020, 10(1):2922.

33. Fallon A, Dukelow T, Kennelly SP, O'Neill D: COVID-19 in nursing homes. QJM : monthly journal of the Association of Physicians 2020, 113(6):391-392.

34. Werner RM, Hoffman AK, Coe NB: Long-Term Care Policy after Covid-19 - Solving the Nursing Home Crisis. The New England journal of medicine 2020, 383(10):903-905.

35. He M, Li Y, Fang F: Is There a Link between Nursing Home Reported Quality and COVID-19 Cases? Evidence from California Skilled Nursing Facilities. J Am Med Dir Assoc 2020, 21(7):905-908.

36. Li Y, Temkin-Greener H, Shan G, Cai X: COVID-19 Infections and Deaths among Connecticut Nursing Home Residents: Facility Correlates. J Am Geriatr Soc 2020, 68(9):1899-1906.

37. Chen W, Wang Q, Li YQ, Yu HL, Xia YY, Zhang ML, Qin Y, Zhang T, Peng ZB, Zhang RC et al: Early containment strategies and core measures for prevention and control of novel coronavirus pneumonia in China. Chinese journal of preventive medicine 2020, 54(3):239-244.

38. Matias T, Dominski FH, Marks DF: Human needs in COVID-19 isolation. Journal of Health Psychology 2020, 25(7):871-882.

39. Bridges CB, Kuehnert MJ, Hall CB: Transmission of influenza: Implications for control in health care settings. Clin Infect Dis 2003, 37(8):1094-1101.

40. Fu SL: Investigation Report on Survival Status and Predicament of Elderly Caregivers. Family Services 2020(06):42-46.

41. Cohrs C, Bormann KC, Diebig M, Millhoff C, Pachocki K, Rowold J: Transformational leadership and communication Evaluation of a two-day leadership development program. Leadership \& Organization Development Journal 2020, 41(1):101-117.

42. Kampf G, Todt D, Pfaender S, Steinmann E: Persistence of coronaviruses on inanimate surfaces and their inactivation with biocidal agents. Journal of Hospital Infection 2020, 104(3):246-251.

43. Khachfe HH, Chahrour M, Sammouri J, Salhab HA, Makki BE, Fares MY: An Epidemiological Study on COVID-19: A Rapidly Spreading Disease. Cureus 2020, 12(3):e7313.

44. West R, Michie S, Rubin GJ, Amlot R: Applying principles of behaviour change to reduce SARS-CoV-2 transmission. Nature Human Behaviour 2020, 4(5):451-459.

45. Song Jiang-nan CG-q, YIn Jin, Gao Qiong, Dai Jun-bin.: Implementation of disinfection treatment in the isolation places of coronavirus disease 2019. Practical Preventive Medicine 2020, 27(4):400-402.

46. Natural ventilation for infection control in health-care settings. World Health Organization. [https:// www.ncbi.nlm.nih.gov/books/NBK143281/]

47. van Doremalen N, Bushmaker T, Morris DH, Holbrook MG, Gamble A, Williamson BN, Tamin A, Harcourt JL, Thornburg NJ, Gerber SI et al: Aerosol and Surface Stability of SARS-CoV-2 as Compared with SARS-CoV-1. New England Journal of Medicine 2020, 382(16):1564-1567.

48. Coe NB, Van Houtven CH: Living Arrangements of Older Adults and COVID-19 Risk: It Is Not Just Nursing Homes. Journal of the American Geriatrics Society 2020, 68(7):1398-1399. 


\section{Basic management}

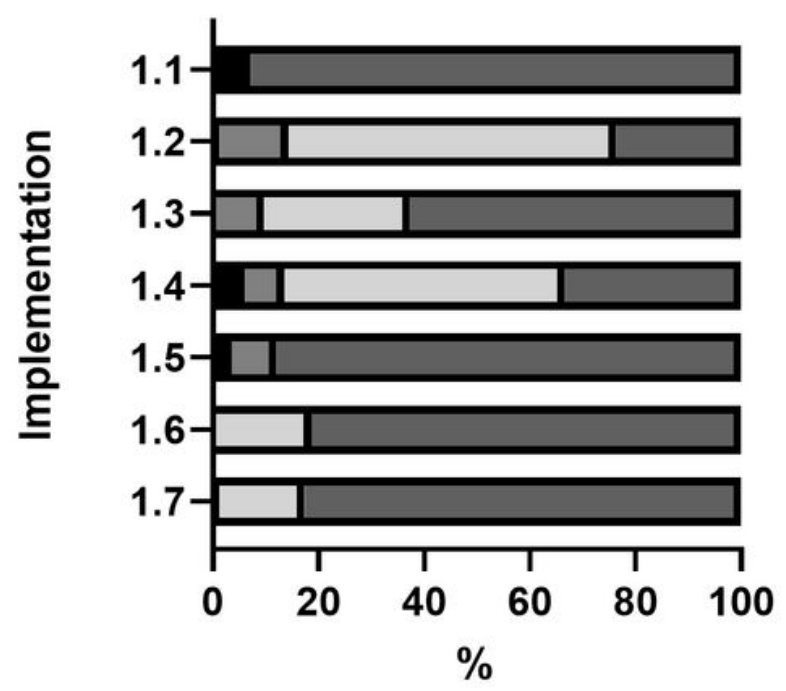

\section{Environmental disinfection} management

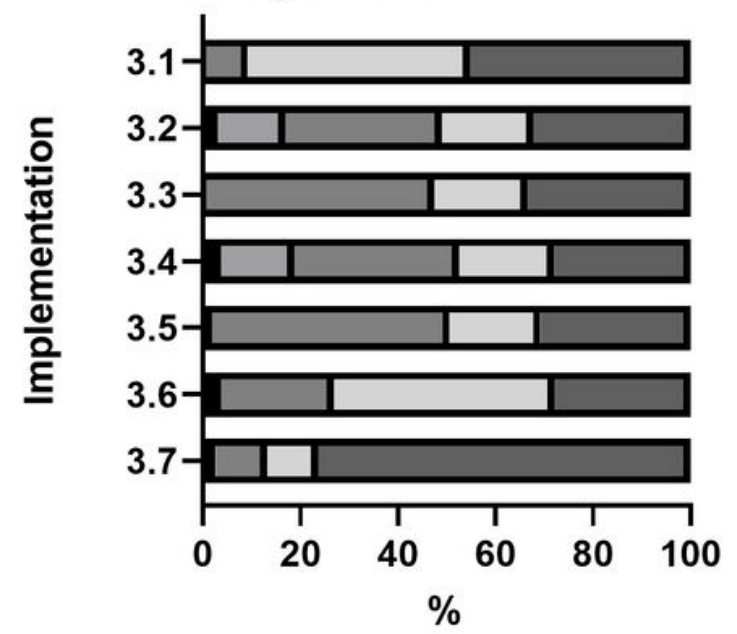

ㅁ always $\boldsymbol{\square}$ most of time $\boldsymbol{\square}$ sometimes

\section{Access management}

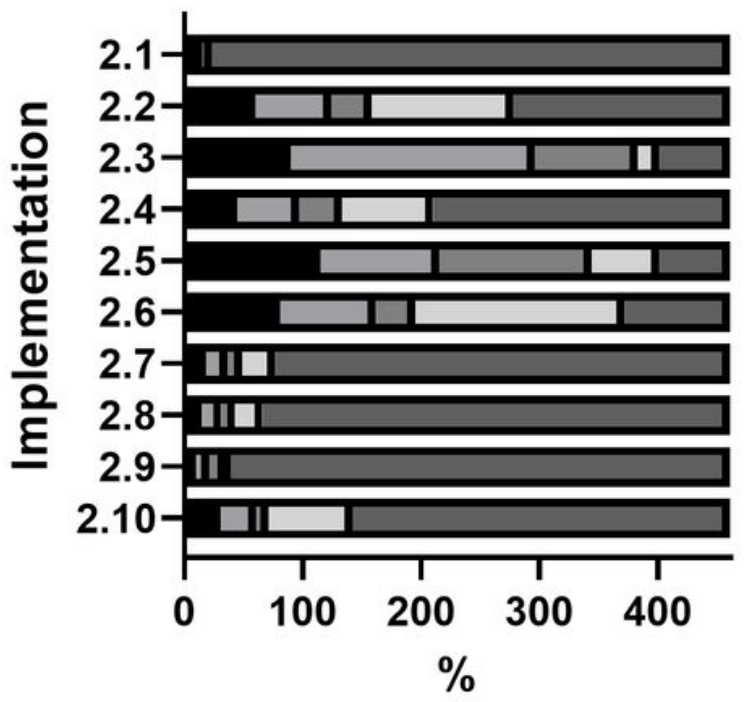

4 Hygiene behaviour management

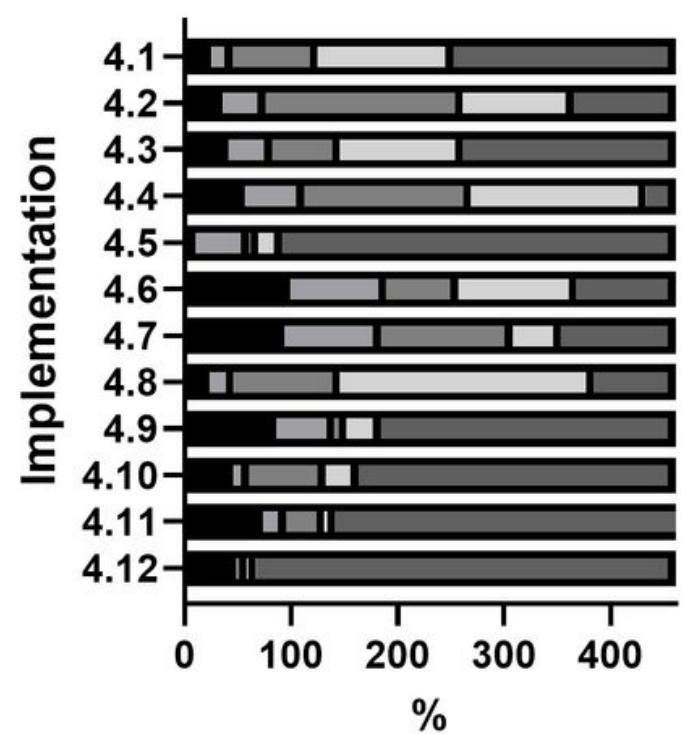

口 rarely $\square$ never

Figure 1

Implementation proportion of four aspects Note: Items' detailed content was referred in table 3. 
Lack of protective supplies(face masks, gloves,alcohol,and disinfectant) - 72.0

Lack of staff (medical staff, nurse aides, and other staff)- 47.7

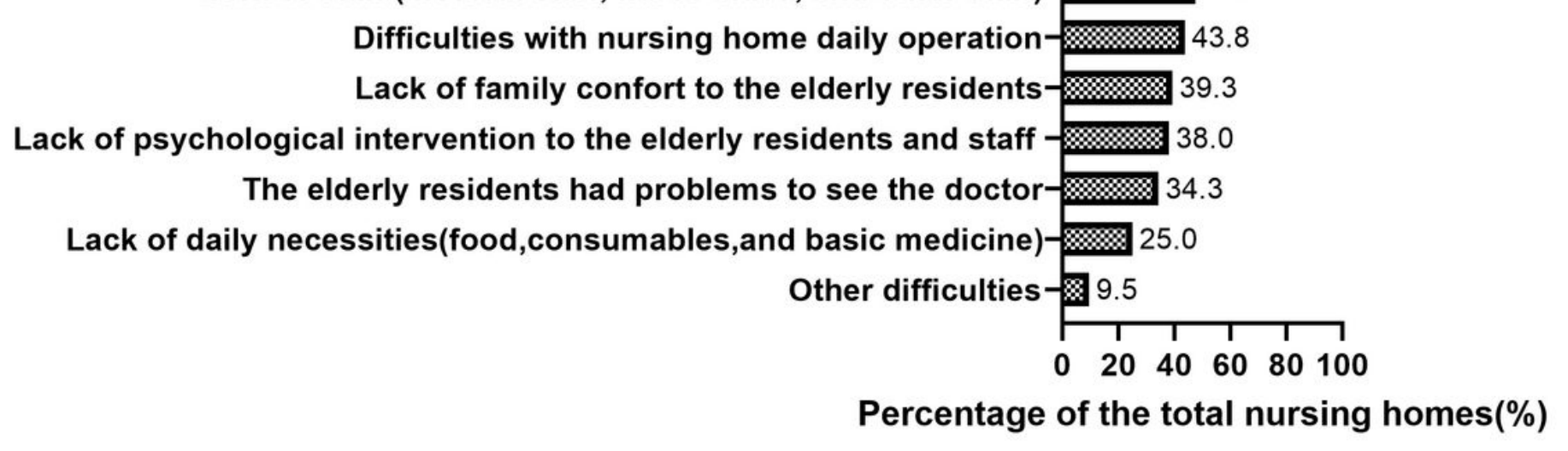

Figure 2

Resource problems of nursing homes in china 69.8\% (332/461) of nursing home managers reported they had serious resource problems, $30.2 \%$ (139/461) of nursing home managers reported they had not been involved in serious resource problems. We used binary logistic regression analysis to find the factors related to the nursing home with serious resource problems (Table 5). The result showed nursing home located in urban ( $\mathrm{OR}=0.315,95 \% \mathrm{Cl}: 0.127 \sim 0.779)$, nursing home size is large (more than 200 beds) $(\mathrm{OR}=0.232,95 \% \mathrm{Cl}: 0.129 \sim 0.419)$, have hospital-nursing home cooperation and manager's transformational leadership score $>60(\mathrm{OR}=0.577,95 \% \mathrm{Cl}: 0.343 \sim 0.970)$ were protective factors. Nursing homes with these factors had a lower risk of involving in serious problems.

\section{Supplementary Files}

This is a list of supplementary files associated with this preprint. Click to download.

- Questionnaire.docx 